\title{
TOXICIDAdE AgUdA DE HeRBICIDAS A TILÁPIA (Oreochromis niloticus) ${ }^{1}$
}

\author{
Acute Toxicity to Herbicides to Oreochromis niloticus
}

\author{
BOTELHO, R.G. ${ }^{2}$, SANTOS, J.B. ${ }^{3}$, OLIVEIRA, T.A. ${ }^{4}$, BRAGA, R.R. ${ }^{5}$ e BYRRO, E.C.M. ${ }^{5}$
}

\begin{abstract}
RESUMO - Esta pesquisa teve como objetivo avaliar a sensibilidade de alevinos de Oreochromis niloticus a diversos herbicidas. Para isso, foram realizados dois ensaios, sendo, no primeiro, avaliadas concentrações de atrazina $\left(0 ; 2,5 ; 5 ; 10 ;\right.$ e $\left.20 \mathrm{mg} \mathrm{L}^{-1}\right)$, visando a determinação da concentração letal a $50 \%$ dos indivíduos $\left(\mathrm{CL}_{50}\right)$, e, no segundo, a sensibilidade às mesclas dos herbicidas alachlor + atrazina $\left(5,33+5,33 \mathrm{mg} \mathrm{L}^{-1}\right)$, diuron + MSMA $(5,33+$ $\left.2,13 \mathrm{mg} \mathrm{L}^{-1}\right)$, paraquat $\left(1,33 \mathrm{mg} \mathrm{L}^{-1}\right)$ e 2,4-D + picloram $\left(1,28+0,34 \mathrm{mg} \mathrm{L}^{-1}\right)$, com contagem de mortes 96 horas após exposição aos produtos. No primeiro ensaio foi observado elevado declínio na sobrevivência dos alevinos a partir de $3 \mathrm{mg} \mathrm{L}^{-1}$ do herbicida atrazina, com $\mathrm{CL}_{50}$ estimada de 5,02 $\mathrm{mg} \mathrm{L}^{-1}$. No segundo, a mistura alachlor + atrazina promoveu o maior efeito de mortalidade sobre os alevinos de tilápia. Com 72 horas de exposição, a escala de intoxicação evidenciou redução nos números de indivíduos de, aproximadamente, 17,4\% para os produtos paraquat, 2,4-D + picloram e diuron + MSMA e de 100\% para alachlor + atrazina. Os dados permitem concluir que a $\mathrm{CL}_{50}$ obtida para o atrazina é inferior àquela mencionada como tóxica para truta e que a mistura alachlor + atrazina pode ser caracterizada como de risco para O. niloticus, mesmo quando aplicada em doses normais de uso.
\end{abstract}

Palavras-chave: alachlor, atrazina, 2,4-D, diuron, paraquat, picloram.

ABSTRACT - Two assays were carried out to evaluate Oreochromis niloticus sensitivity to different herbicides. In the first experiment, atrazin concentrations (0; 2.5; 5; 10 and $\left.20 \mathrm{mg} \mathrm{L}^{-1}\right)$ were evaluated aiming to determine lethal concentration (LC50) to $O$. niloticus. In the second assay, the effects of the herbicide mixtures alachlor + atrazin $\left(5.33+5.33 \mathrm{mg} \mathrm{L^{-1 }}\right)$, diuron + MSMA $(5.33+$ $\left.2.13 \mathrm{mg} \mathrm{L}^{-1}\right)$, paraquat (1.33 $\left.\mathrm{mg} \mathrm{L}^{-1}\right)$ and 2,4-D + picloran $\left(1.28+0.34 \mathrm{mg} \mathrm{L}^{-1}\right)$, were evaluated on O. niloticus survival after $96 \mathrm{~h}$ of exposure. In the first assay, a sharp decrease in fingerlings survival was observed from $3 \mathrm{mg} \mathrm{L}^{-1}$ of atrazin with $C L_{50}$ value of $5.02 \mathrm{mg} \mathrm{L}^{-1}$ and a high biomass decrease due to herbicide presence. In the second assay, a greater negative effect was observed on fingerlings by alachlor + atrazin. . After 72 h of incubation, intoxication rate showed a reduction in the number of individuals of $17.4 \%$ for paraquat, 2, $4 \mathrm{D}+$ picloram and diuron $+M S M A$, and of $100 \%$ for alachlor + atrazin. It was concluded that $C L_{50}$ obtained for atrazin is inferior to that listed as toxic to trouts and that the alachlor + atrazin mixture can be characterized as a risk to $\mathbf{O}$. niloticus, even when applied at commercially recommended rates.

Keywords: alachlor, atrazin, 2,4-D, diuron, paraquat, picloram.

\section{INTRODUÇÃO}

Em áreas agrícolas, o carregamento de águas superficiais e a lixiviação da água intersticial para rios e lagos podem introduzir nutrientes (a partir de fertilizantes) e agrotóxicos em quantidades substanciais (Tomita $\&$ Beiruth, 2002). Considerando sistemas de

1 Recebido para publicação em 9.6.2008 e na forma revisada em 15.5.2009.

2 Pós-Graduando do curso de Ciências Biológicas da Universidade Vale do Rio Doce - UNIVALE. Governador Valadares-MG, $<$ rafaelgrossib@hotmail.com>; ${ }^{3}$ Professor Adjunto do Dep. de Agronomia da Universidade Federal dos Vales do Jequitinhonha e Mucuri - UFVJM, Campus JK, Rodovia MGT 367 - Km 583, 39100-000 Diamantina-MG, <jbarbosa@ufvjm.edu.br>; ${ }^{4}$ Bióloga, Pós-Graduanda do Instituto Nacional de Pesquisas da Amazônia - INPA, Manaus-AM, <taciane.almeida@yahoo.com.br>. ${ }^{5}$ Graduandos do curso de Agronomia da UFVJM, Diamantina-MG. 
consorciação, a integração lavoura-pecuária (ILP) vem se destacando pelo melhor uso do solo e diminuição na quantidade total de agrotóxicos empregada para controle de pragas, doenças e plantas daninhas (Lustosa \& Rocha, 2007). Nesse sistema, o milho se destaca como principal cultura associada às forrageiras, e o herbicida atrazina é o mais recomendado para aplicação em razão do baixo custo, eficácia no controle de plantas daninhas, facilidade de utilização, seletividade para o milho e baixa permanência no solo em relação a outros produtos que são aplicados nas pastagens convencionais, como picloram, fluroxipire e $2,4-\mathrm{D}$, que têm persistência de até três anos (Sprague et al., 2000; Rodrigues \& Almeida, 2005).

O risco de a molécula de atrazina lixiviar e atingir cursos de água é amplamente discutido (Sprague et al., 2000; Pinho et al., 2007). Testes de toxicidade em ambientes aquáticos têm sido bastante empregados a fim de determinar efeitos deletérios de poluentes em organismos aquáticos. Segundo Tomita \& Beiruth (2002), testes de toxicidade aguda são experimentos de curta duração que proporcionam rápidas respostas em estudos sobre efeitos tóxicos letais, cujo objetivo é determinar a concentração letal média $\left(\mathrm{CL}_{50}\right)$ de uma substância sobre organismos aquáticos, num período de 24 a 96 horas de exposição.

Pela ampla disseminação como organismo cultivado, resistência a variações de temperatura e de oxigênio dissolvido na água e facilidade de aquisição (Lovshin, 1997; Meurer et al., 2000), a tilápia, especialmente Oreochromis niloticus, tem se destacado no Brasil. Nesse sentido, torna-se necessário, para as condições tropicais, avaliar o efeito do atrazina e outros herbicidas comumente usados na cultura do milho e nos sistemas ILP sobre esse organismo - representativo da fauna aquática. O estudo da sensibilidade da tilápia a herbicidas pode contribuir para definila como espécie bioindicadora de resíduos desses produtos ou identificá-la como organismo-alvo no biomonitoramento de herbicidas em ambiente aquático. Este trabalho teve como objetivos estimar a $\mathrm{CL}_{50}$ de atrazina para alevinos de $O$. niloticus e avaliar o potencial de intoxicação de misturas comerciais dos herbicidas alachlor + atrazina, diuron + MSMA, paraquat e 2,4-D + picloram.

\section{MATERIAL E MÉTODOS}

O trabalho foi realizado em laboratório da Faculdade de Ciências Biológicas-FACE da Universidade Vale do Rio Doce (UNIVALE), Governador Valadares-MG. Foram estabelecidos dois ensaios, em períodos diferentes, com alevinos de tilápia (Oreochromis niloticus) medindo entre 1,5 e $3 \mathrm{~cm}$, com aproximadamente 20 dias de idade.

No primeiro ensaio foi avaliada a toxicidade aguda do herbicida atrazina à tilápia. Para isso, foi utilizada a formulação comercial Siptran 500 SC ${ }^{\circledR}$, contendo $50 \%$ do produto técnico atrazina. As características do produto formulado são: solubilidade na água: $33 \mathrm{mg} \mathrm{L}^{-1}$ a $22{ }^{\circ} \mathrm{C}$; e pH 7 ; pressão de vapor de $2,9 \times 10^{-7}$ $\mathrm{mm} \mathrm{Hg}$ a $25^{\circ} \mathrm{C} \mathrm{e} \mathrm{K}_{\mathrm{OC}}$ de $100 \mathrm{~mL} \mathrm{~g}^{-1}$ (Rodrigues \& Almeida, 2005). A solução-estoque do herbicida foi preparada pela mistura da formulação comercial com água destilada. As concentrações utilizadas do produto foram de $0 ; 2,5$; 5; 10; e $20 \mathrm{mg} \mathrm{L}^{-1}$ de atrazina, calculadas com base na dosagem média estabelecida como tóxica para trutas - $\mathrm{Cl}_{50}$ (Rodrigues \& Almeida, 2005). Quanto à avaliação dos testes de intoxicação aguda do herbicida sobre o peixe, seguiu-se metodologia adaptada das normas contidas em Ferreira (2003).

No segundo ensaio, foram testadas as misturas comerciais: Agimix ${ }^{\circledast}\left(260 \mathrm{~g} \mathrm{~L}^{-1} \mathrm{de}\right.$ alachlor $+260 \mathrm{~g} \mathrm{~L}^{-1}$ de atrazina), Fortex $\mathrm{SC}^{\circledR}$ (140 $\mathrm{g} \mathrm{L}^{-1}$ de diuron $+360 \mathrm{~g} \mathrm{~L}^{-1}$ de MSMA), Gramoxone $^{\circledR}\left(200 \mathrm{~g} \mathrm{~L}^{-1}\right.$ de paraquat) e Tordon ${ }^{\circledR}$ (240 $\mathrm{g} \mathrm{L}^{-1} \mathrm{de} 2,4-\mathrm{D}+64 \mathrm{~g} \mathrm{~L}^{-1}$ de picloram). Nesse caso, os tratamentos foram compostos por quatro formulações de herbicidas mais uma testemunha sem herbicida. A concentração final (mg L $\left.{ }^{-1}\right)$ de cada produto/mistura foi a seguinte [baseada na concentração relatada por Rodrigues \& Almeida (2005) para testes de toxicidade $-\mathrm{CL}_{50}$ para exemplares de peixes]: alachlor + atrazina, 5,33 +5,33 $\mathrm{mg} \mathrm{L}^{-1}$; diuron + MSMA, 5,33 + 2,13 $\mathrm{mg} \mathrm{L}^{1}$; paraquat, $1,33 \mathrm{mg} \mathrm{L}^{-1}$; e 2,4-D + picloram, 1,28 + $0,34 \mathrm{mg} \mathrm{L}^{-1}$.

Em ambos os ensaios, as concentrações finais dos produtos foram adicionadas em bandejas com formato retangular e dimensões de $40 \times 20 \times 10 \mathrm{~cm}$ (comprimento $\mathrm{x}$ largura $x$ altura), em material PVC. Em cada bandeja foram colocados cinco indivíduos. 
O experimento foi instalado no delineamento inteiramente casualizado com cinco repetições (bandejas), totalizando 25 unidades experimentais para cada ensaio. Para aplicação da solução contendo o herbicida, utilizou-se pipeta de precisão com pipetador automático.

Durante o período de avaliação, as bandejas foram mantidas com iluminação artificial e fotoperíodo de 12 horas. As bandejas foram equipadas com sistema de aeração individual. A temperatura da água foi medida diariamente com termômetro de coluna de mercúrio com escala de $-38 \mathrm{a}+50{ }^{\circ} \mathrm{C}$. Diariamente, os alevinos foram contados, sendo retirados os que se encontravam mortos. O período de exposição dos animais ao produto foi de 96 horas, para determinação da $\mathrm{CL}_{50}$.

No primeiro ensaio, os alevinos foram pesados antes e no final do período de exposição (120 horas). As médias resultantes da mortalidade por tempo de exposição às concentrações do herbicida foram submetidas à análise de variância pelo teste $\mathrm{F}$. A taxa de mortalidade foi estimada por meio de regressão (log-logística), atendendo aos requisitos para significância dos coeficientes (teste t a $5 \%$ de probabilidade) e adequação ao comportamento biológico, estabelecendo-se também a concentração do produto letal a $50 \%$ dos indivíduos $\left(\mathrm{CL}_{50}\right)$, por meio do programa Trimed Spearman Karber (Hamilton et al., 1977).

No segundo ensaio, realizou-se análise de variância para os dados de número de animais que sobreviveram em cada bandeja a cada 24 horas. As médias dos tratamentos, para as características avaliadas, foram comparadas pelo teste de Tukey a $5 \%$ de probabilidade. Também foram estimadas regressões relacionando mortalidade e tempo de exposição dos alevinos aos herbicidas.

\section{RESULTADOS E DISCUSSÃO}

Observando a função log-logística $(P<0,05)$, percebe-se o elevado declínio na sobrevivência dos alevinos a partir da concentração de aproximadamente $2 \mathrm{mg} \mathrm{L}^{-1}$ do produto atrazina, considerada baixa, com $\mathrm{CL}_{50}$ estimada em 5,02 $\mathrm{mg} \mathrm{L}^{-1}$ (Figura 1).

Segundo Rodrigues \& Almeida (2005), o herbicida atrazina apresenta 9,9 $\mathrm{mg} \mathrm{L}^{-1}$ como valor de $\mathrm{CL}_{50}$ para trutas - espécie típica de clima temperado que se desenvolve em temperatura média menor que $15{ }^{\circ} \mathrm{C}$. Considerando que a temperatura influencia os processos de toxicidade dos herbicidas sobre os organismos, sendo maior em condições tropicais, onde a atividade metabólica é mais intensa (Silva et al., 2007), pode-se afirmar que os valores aferidos para $\mathrm{CL}_{50}$ em condições de clima temperado serão mais altos se comparados aos de condições tropicais.

Em trabalho realizado por Boock \& Machado Neto (2005) com fungicida à base de oxicloreto de cobre, as sobrevivências de exemplares de Poecilia reticulata (guaru) foram avaliadas em ambientes contendo concentrações crescentes desse produto. Após 96 horas de exposição, esses autores estimaram a $\mathrm{CL}_{50}$ em 0,1 $\mathrm{mg} \mathrm{L}^{-1}$, valor esse extremamente baixo, quando comparado a herbicidas. No entanto, no caso dos herbicidas, a maior relevância nos estudos de ecotoxicologia está em função da quantidade total aplicada anualmente no ambiente, que chega a ser, pelo menos, quatro vezes mais do que aquela observada para fungicidas (Sindag, 2006).

Em outro estudo, Hussar et al. (2004) avaliaram a dosagem tóxica do fungicida tebuconazole sobre juvenis de Tilapia rendalli (tilápia) e de Piaractus mesopotamicus (pacu), observando, em ambos os casos, velocidade e taxa de mortalidade proporcionais ao aumento da concentração do produto.

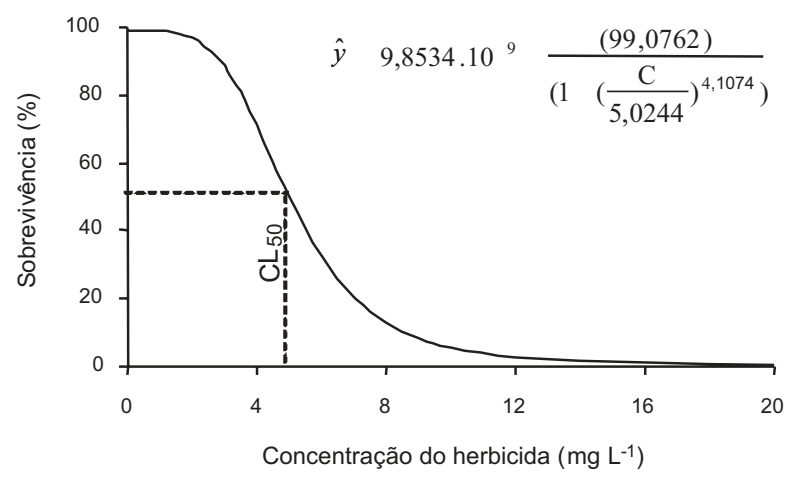

Figura 1 - Porcentagem de sobrevivência de alevinos de tilápia (Oreochromis niloticus) após 96 horas da aplicação de concentrações (C) crescentes de atrazina (significativo pelo teste $\mathrm{t}$ a $5 \%$ de probabilidade, com $\left.\mathrm{R}^{2}=0,99\right)$. Governador Valadares, 2007. 
Considerando o valor referencial de $\mathrm{CL}_{50}$ do atrazina de 9,9 $\mathrm{mg} \mathrm{L}^{-1}$ para trutas (Rodrigues \& Almeida, 2005), o uso dessa concentração resultaria em taxa de mortalidade superior a 94\% neste estudo, evidenciando a maior sensibilidade de $O$. niloticus a esse herbicida. Observando a Figura 1, pode-se estabelecer a concentração aproximada de $8,55 \mathrm{mg} \mathrm{L}^{-1}$ como aquela suficiente para a morte de $90 \%$ dos indivíduos.

Além dos fatores mencionados (temperatura e classe de pesticidas), existe ainda a sensibilidade diferenciada dos organismos aquáticos ao mesmo pesticida. Para Oulmi et al. (1995), a exposição da espécie de truta Oncorhynchus mykiss ao atrazina resultou em $50 \%$ de mortalidade em concentração próxima a $10 \mathrm{mg} \mathrm{L}^{-1}$; contudo, no teste com embriões desse mesmo peixe esse valor diminuiu para $1 \mathrm{mg} \mathrm{L}{ }^{-1}$. Para Prassad \& Reddy (1994), a CL $\mathrm{CL}_{50}$ observada para o atrazina sobre Tilapia mossambicus foi de $8,8 \mathrm{mg} \mathrm{L}^{-1}$. Outros trabalhos envolvendo o atrazina evidenciaram os seguintes valores de $\mathrm{CL}_{50}\left(\mathrm{mg} \mathrm{L}^{-1}\right)$ : 18,8 para Cyprinus carpio (Neskovic et al., 1993) e 10,2 para Rhamdia quelen (Kreutz et al., 2008).

Avaliando a variação de peso observada entre o início da incubação dos alevinos e 120 horas de exposição, observa-se diminuição acentuada de massa corporal em função da presença do herbicida. À exceção do controle (sem herbicida), todas as concentrações promoveram perda de peso nos peixes de, no mínimo, $60 \mathrm{mg}$ por indivíduo (Figura 2). Para

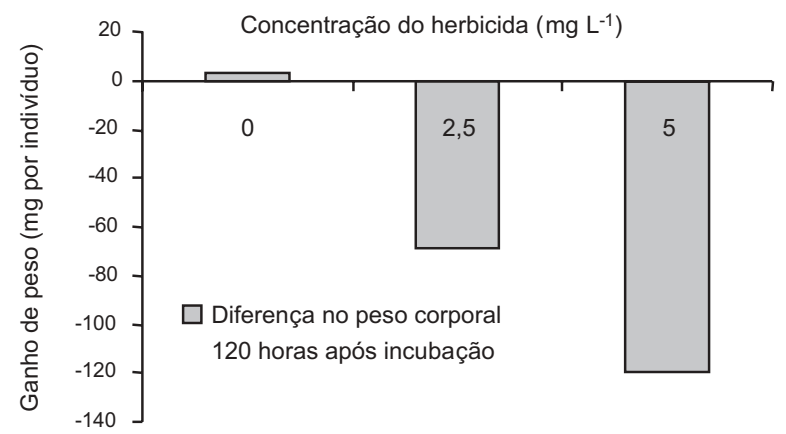

Figura 2 - Variação no peso corporal (significativo pelo teste de Tukey a $5 \%$ de probabilidade) de alevinos de tilápia (Oreochromis niloticus) após 120 horas da aplicação de doses crescentes de atrazina. Nas maiores concentrações (10 e $20 \mathrm{mg} \mathrm{L}^{-1}$ ), o índice de mortalidade atingiu 100\%. Governador Valadares, 2007 as concentrações entre 10 e $20 \mathrm{mg} \mathrm{L}^{-1}$ não foi estimada a massa corporal, em razão de não haver indivíduos vivos após o tempo de exposição.

A perda de massa corporal pode estar associada à maior dificuldade em metabolizar os alimentos, em razão da presença de moléculas tóxicas e da peroxidação de lipídeos celulares pelos componentes tóxicos presentes na formulação do herbicida. Em tecidos animais, acontecem reações que visam produzir energia para as células. Nessas reações são formados os radicais livres instáveis, que atacam outras moléculas, como lipídios, material genético e proteínas, acelerando a oxidação de tecidos e provocando lesões nas células. A maioria dos pesticidas possui essa propriedade de formação de radicais livres. Essa hipótese explicaria o escurecimento dos peixes nas maiores concentrações testadas (dados não apresentados). Segundo Larini (1997), as triazinas podem provocar fraqueza muscular, perda de peso e dificuldade respiratória em animais - sintomas também observados em alevinos submetidos às maiores concentrações do atrazina (10 e $20 \mathrm{mg} \mathrm{L}^{-1}$ ).

No segundo ensaio, independentemente da aplicação de herbicidas, foi observada baixa taxa de mortalidade dos peixes com o tempo de exposição. Ao final de 96 horas, $17 \%$ dos individuos morreram na testemunha, sendo tal fato atribuído ao pouco tempo de adaptação de $O$. niloticus às condições laboratoriais (dois dias). Contudo, esse índice pode ser considerado baixo, não interferindo na comparação dos resultados expressos em porcentagem, uma vez que todos os demais tratamentos tiveram indice superior de mortalidade.

Após 24 horas de exposição, observou-se que o produto comercial Tordon ${ }^{\circledR}$ foi a única formulação que promoveu mortes, estabilizando-se nas avaliações posteriores. A partir de 48 horas da aplicação dos produtos, a mistura alachlor + atrazina promoveu o maior efeito negativo sobre os alevinos, sendo superior a $80 \%$ (Tabela 1). Considerando os efeitos do atrazina, é provável que sua mistura ao alachlor explique o efeito mais pronunciado sobre o total de indivíduos mortos. O alachlor é, entre os herbicidas testados, aquele que possui menor valor de $\mathrm{CL}_{50}$ para peixes 
Tabela 1 - Índice de sobrevivência de alevinos de tilápia (Oreochromis niloticus) após 96 horas de exposição em solução contendo diferentes formulações comerciais de herbicidas, aplicados em dose equivalente à recomendada pelo fabricante. Governador Valadares, 2007

\begin{tabular}{|l|c|c|c|c|}
\hline \multirow{2}{*}{ Tratamento } & \multicolumn{4}{|c|}{ Sobrevivência de alevinos (\%) em solução } \\
\cline { 2 - 5 } & \multicolumn{4}{|c|}{ (Horas após o início da exposição) } \\
\cline { 2 - 5 } & 24 & 48 & 72 & 96 \\
\hline Testemunha & $100,00 \mathrm{a}$ & $95,65 \mathrm{a}$ & $91,30 \mathrm{a}$ & $82,60 \mathrm{a}$ \\
\hline Gramoxone $^{\circledR}$ & $91,30 \mathrm{a}$ & $86,95 \mathrm{ab}$ & $82,60 \mathrm{ab}$ & $82,60 \mathrm{a}$ \\
\hline Tordon $^{\circledR}$ & $86,95 \mathrm{~b}$ & $78,26 \mathrm{~b}$ & $78,26 \mathrm{~b}$ & $78,26 \mathrm{~b}$ \\
\hline Agimix $^{\circledR}$ & $95,65 \mathrm{a}$ & $17,39 \mathrm{c}$ & $0,00 \mathrm{c}$ & $0,00 \mathrm{c}$ \\
\hline Fortex $^{\circledR}$ & $91,30 \mathrm{a}$ & $91,30 \mathrm{a}$ & $86,95 \mathrm{ab}$ & $86,95 \mathrm{a}$ \\
\hline
\end{tabular}

Médias seguidas por letras iguais, em cada coluna, não diferem entre si pelo teste de Tukey a $5 \%$ de probabilidade.

(Rodrigues \& Almeida, 2005), sendo, aproximadamente, a metade daquele estimado para o atrazina e entre 1 e $2 \%$ da concentração estimada para o 2,4-D (maior $\mathrm{CL}_{50}$ entre os herbicidas testados) (Rodrigues \& Almeida, 2005).

Com 72 horas de exposição, a escala de intoxicação evidenciou redução no número de indivíduos de, aproximadamente, 17,4\% para o paraquat, 2,4-D + picloram e diuron + MSMA e de $100 \%$ para o alachlor + atrazina, comprovando o efeito altamente tóxico desta mistura. Em estudo feito por Houseworth \& Tweedy (1972), observou-se redução de 37\% de Fusarium oxysporum em meio contendo alachlor, evidenciando menor especificidade do herbicida em relação aos organismos - não alvo.

Analisando a relação entre a sobrevivência (\%) e o tempo após a exposição aos herbicidas, percebe-se que Agimix $^{\circledR}$ foi a única formulação letal aos alevinos a partir de 48 horas (Figura 3). Quanto aos demais tratamentos, a resposta em números de indivíduos apresentou decréscimo linear, com coeficiente angular da reta aproximado de 0,177 (Figura 3, com $\mathrm{P}<0,05)$.

A partir do teste de identidade de modelos (Regazzi, 1996), à exceção de alachlor + atrazina, todas as demais formulações apresentaram o mesmo padrão de toxicidade, sendo ajustadas numa mesma reta (Figura 3). Sintomas como irritação nas narinas foram observados em grande parte dos alevinos sob efeito da mistura 2,4-D + picloram (aspecto avermelhado nas narinas - dados não apresentados).

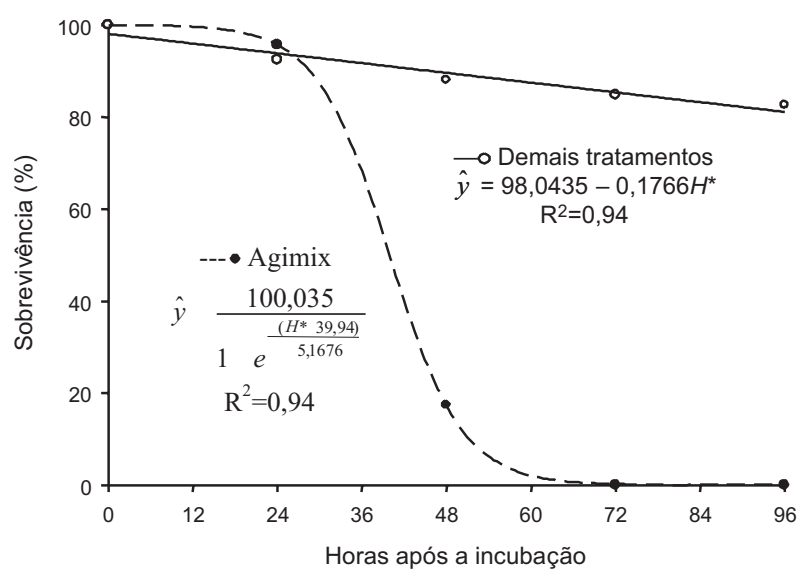

* significativo pelo teste $\mathrm{t}$ a $5 \%$ de probabilidade.

Figura 3 - Relação entre sobrevivência (\%) de alevinos de Oreochromis niloticus e tempo (horas $=\mathrm{H}$ ) após a exposição, sob efeito do herbicida Agimix ${ }^{\circledR}$ e demais tratamentos (significativamente iguais segundo teste de identidade de modelos, REGAZZI, 1996).

Quanto ao paraquat, estudos comprovam seu efeito tóxico, promovendo a falta de coordenação dos movimentos de animais testados em laboratório (Larini, 1997). Com exceção da mistura alachlor + atrazina, a ausência de sintomas que comprovem maior efeito tóxico das formulações testadas pode ser devido à concentração utilizada de cada herbicida ou atribuída à tolerância de $O$. niloticus a eles.

Pode-se concluir que a $\mathrm{CL}_{50}$ obtida para o atrazina sobre $O$. niloticus é inferior àquela já mencionada para trutas como referencial para fauna aquática e que a mistura alachlor + atrazina pode ser caracterizada como de risco para o organismo testado, mesmo quando contaminar cursos de água com as doses comercialmente recomendadas para as culturas registradas.

\section{AGRADECIMENTOS}

À Fapemig e ao CNPq, pelo apoio financeiro à realização desta pesquisa. À NUTRIVAL, na pessoa do Sr. Lelis Marcelo Duarte, pelo fornecimento dos herbicidas.

\section{LITERATURA CITADA}

BOOCK, M. V.; MACHADO NETO, J. G. Estudos sobre a toxicidade aguda do oxicloreto de cobre para o peixe Poecilia reticulata. B. Inst. Pesca, v. 31, n. 1, p. 29-35, 2005. 
FERREIRA, C. M. Teste de toxicidade aquática para monitoramento ambiental. Biológico, v. 65, n. 1/2, p. 17-18, 2003.

HAMILTON, M. A.; RUSSO, R. C.; THURSTON, V. Trimed Spearman-Karber method for estimating medial lethal concentrations in toxicity bioassays. Environ. Sci. Technol. v. 7, n. 2, p. 714-719, 1977.

HOUSEWORTH, L. D.; TWEEDY, B. G. Effect of herbicides on soil-borne pathogens. Phytopathology, v. 62, n. 4, p. $765-775,1972$.

HUSSAR, G. J. et al. Ensaio para determinação de dosagem tóxica do fungicida tebuconazole (Folicur 200CE) sobre alevinos e juvenis de tilápia (Tilapia rendalli) e de pacu (Piaractus mesopotamicus). Eng. Amb., v. 1, n. 1, p. 35-44, 2004.

KREUTZ, L. C. et al. Acute toxicity test of agricultural pesticides on silver catfish (Rhamdia quelen) fingerlings. Ci. Rural, v. 38, n. 4, p. 1050-1055, 2008.

LARINI, L. Toxicologia. 3.ed. São Paulo: Manole, 1997. $301 \mathrm{p}$.

LOVSHIN, L. L. Tilapia farming: A growing worldwide aquaculture industry. In: SIMPÓSIO SOBRE MANEJO E NUTRIÇÃO DE PEIXES, 1., 1997, Piracicaba. Anais... Piracicaba: CBNA, 1997. p. 137-164.

LUSTOSA, J.; ROCHA, A. Integração lavourapecuária. Brasília: MAPA/ABEAS, 2007. 38 p.

(Boletim Técnico)

MEURER, F. et al. Utilização de levedura spray dried na alimentação de alevinos de tilápia do Nilo

(Oreochromis niloticus L.). Acta Sci., v. 22, n. 2, p. 479-484, 2000 .
NESKOVIC, N. K. et al. Acute and subacute toxicity of atrazine to carp. Ecotoxicol. Environ. Safety, v. 25, n. 2, p. 173-182, 1993.

OULMI, Y.; NEGELE, R. D.; BRAUNBECK, T. Segment specificity of the cythological response in rainbow trout (Oncorhyncus mykiss) renal tubules following prolonged exposure to sublethal concentrations of atrazina. Ecotoxicol. Environ. Safety, v. 32, n. 1, p. 39-50, 1995.

$\mathrm{PINHO}, \mathrm{A}$. P. et al. Atrazina and picloram adsorption in organic horizon forest samples under laboratory conditions. Planta Daninha, v. 25, n. 1, p. 125-131, 2007.

PRASSAD, T. A. V.; REDDY, D. C. Atrazina toxicity on hydromineral balance of fish, Tilapia mossambicus. Ecotoxicol. Environ. Safety, v. 28, n. 3, p. 313-316, 1994.

REGAZZI, A. J. Teste para verificar a identidade de modelos de regressão. Pesq. Agropec. Bras., v. 31, n. 1, p. 1-17, 1996

RODRIGUES, B. N.; ALMEIDA, F. S. Guia de herbicidas. 5.ed. Londrina: Grarfmake, 2005. 591 p.

SILVA, A. A. et al. Biologia de plantas daninhas In: SILVA, A. A.; SILVA, J. F. Tópicos em manejo de plantas daninhas. Viçosa, MG: Universidade Federal de Viçosa, 2007. 367 p.

SINDAG. 2006. Disponível em <http://www.sindag.com.br/>. Acesso em: 05 jun. 2008

SPRAGUE, L. A.; HERMAN, J. S.; HORNBERGER, G. M. Atrazina adsorption and colloid facilitated transport through the unsaturated zone. J. Environ. Quality, v. 29, n. 5, p. $1632-1641,2000$

TOMITA, R. Y.; BEYRUTH, Z. Toxicologia de agrotóxicos em ambiente aquático. Biológico, v. 64, n. 2, p. 135-142, 2002. 